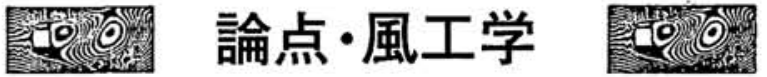

\section{乱流スペクトルの自己回帰モデルへのあてはめについてー1 次元解析の場合一 Fitting AR model for turbulent spectrum}

前田潤 滋*

Junji MAEDA

\section{1. まえがき}

近年, 耐風工学の分野でも自己回帰モデルを使 ったスペクトル解析法 (以下AR法) の利用が広ま っているが, 変動風を解析する立場からの算定精 度に対する議論は岩谷先生 ${ }^{1)}$ を除いてはあまり見 られないように思われる。以前，1次元および2次 元自己回帰法を自然風と風洞乱流に適用した場合 の利点を報告 ${ }^{2)} し ， そ の$ 利用を勧めたことから筆 者も何か話題提供をとの依頼があり, 本コーナー を借りてARモデルによる乱流スペクトルの算定精 度について二, 三報告させて頂くことにした。

AR法の精度検定は目標スペクトルに対する数値 シミュレーションで行われることが多い。この場 合時系列波形を目標スペクトルの逆フーリエ変換 による波形合成によって作成 ${ }^{3)} し$ ，時系列波形の ARモデルから算定されるパワースペクトル（以下 ARスペクトル）と目標スペクトルとの比較によっ てAR法の算定精度を検定するのがよく用いられる 方法である。このとき $\mathrm{AR}$ スペクトルは時系列波形 のARモデルへのあてはめ, いわゆる同定問題を経 て算定される。ARモデルの同定には幾つかのテク ニックが報告されているが, 広く使われている手
法はARモデルのYule-Walker方程式をLevinsonDurbinのアルゴリズムで解き，FPE基準によって AR係数を決定する赤池の方法)である。しかしな がら赤池の方法は時系列波形の相関関数を同定問 題の入力情報として使用するため, 波形合成によ る時系列シミュレーションを用いる精度検定には AR係数の決定までにAR法そのものに起因しない誤 差が混入する可能性がある。すなわち，(1)目標ス ペクトルに対応する時系列波形作成時の誤差と(2) その時系列の相関関数の算定誤差である。

アンサンブル平均による変動風の自己相関関数 の算定誤差については，拙著文献2)で報告してい るが，Fig. 1 にこれを引用した。真の自己相関関 数が指数関数で表わされると仮定した場合の風速 $\mathrm{u}$ 成分の時系列波形のアンサンブル平均から求め られる自己相関関数に含まれる規準化標準誤差を 示したのが同図である。なお，風速 u成分の自己 相関関数が指数関数で表される乱流モデルを筆者 はDryden型と呼んでいる5)。

自己相関関数の標準誤差は波形に含まれる乱れ の積分スケール槛 $\mathrm{x}$ と平均風速 U一およびデータの 評価時間 Tによって異り，一般に標準誤差はタイ

*九州大学工学部, 助手

Research Associate, Faculty of Engineering, Kyushu University.

(本稿受理: 平成 2 年 1 月 16 日) 


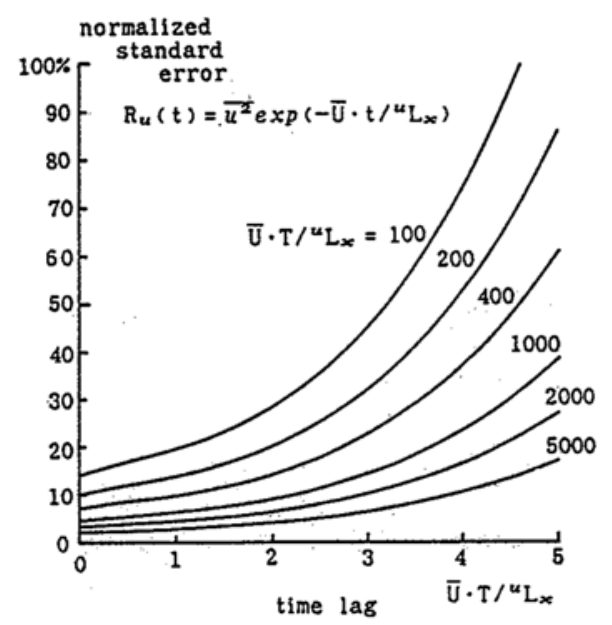

Fig. 1 Standard error of Dryden u component

ムラグ $\mathrm{t}$ の増大とともに急激に大きくなるが, 比 較的小さなタイムラグでも標準誤差を小さくする のは容易ではない。従って上記(1)の時系列シミュ レーション時での誤差を小さく抑えても, 時系列 の相関関数を同定問題の入力として使用する限り, AR法そのものの誤差の性質だけを抽出することは できないのである。

以下, 上記二つの誤差が混入しない精度検定法 を工夫し，二, 三の乱流スペクトルについてARモ デルへのあてはめを定性定量的に検討してみよう。

\section{2. 使用したAR法の精度検定手順}

ARモデルの同定問題において入力となる相関関 数を時系列データから算定せず, 目標スペクトル の理論相関関数を直接使用すれば相関関数に起因 する誤差混入を避けられることに着目し，以下の 手順でAR法による相関係数およびパワースペクト ルの算定精度を検討した。

1. 理論相関関数を無次元時間間隔 $\Delta \tau$ で離散 化し, Yule-Walker方程式をLevinson-Durbinのア ルゴリズムにより解き, AR係数 $\mathrm{a}_{\mathrm{i}}(\mathrm{m}), \mathrm{i}=1,2, \ldots \mathrm{m}$ を算定する。ただし，無次元時間 $\tau$ は次式とした。

$$
\tau=\bar{U} \cdot t /{ }^{P} L_{q}
$$

ここに, Ūは平均風速, ${ }^{P} \mathrm{~L}_{\mathrm{q}}$ は $\mathrm{p}$ 成分 $(\mathrm{u}$ or $\mathrm{v})$ ) $\mathrm{q}$
方向 ( $\mathrm{x}$ or $\mathrm{y}$ )の乱れの積分スケール, $\mathrm{t}$ は実時間 である。また, 離散時刻 $\mathrm{k} て ゙ の$ 時系列の值を $\mathrm{x}_{\mathrm{k}}$, AR係数を $\mathrm{a}_{\mathrm{i}}(\mathrm{m}), \mathrm{i}=1, \cdots, \mathrm{m}$ ，ホワイトノイズを $\mathrm{e}_{\mathrm{k}}$ として次式で定義するm次のARモデルを用いる。

$$
\mathrm{x}_{\mathrm{k}}=\mathrm{e}_{\mathrm{k}}-\sum_{\mathrm{i}=1}^{\mathrm{m}} \mathrm{a}_{\mathrm{i}}(\mathrm{m}) \mathrm{x}_{\mathrm{k}-\mathrm{i}}
$$

2. 得られた $A R$ 係数から $(m+1) \Delta \tau$ 以上の夕イ ムラグの自己相関係数 $\rho_{k}=\rho(k \Delta \tau)$ を次式で算 定し, 理論相関係数と比較する。

$$
\rho_{\mathrm{k}}=-\sum_{\mathrm{i}=1}^{\mathrm{m}} \mathrm{a}_{\mathrm{i}}(\mathrm{m}) \rho_{\mathrm{k}-\mathrm{i}}(\mathrm{k}=\mathrm{m}+1, \mathrm{~m}+2, \cdots)
$$

3. AR係数 $a_{i}(m), i=1, \cdots, m$ を用いて, 無次元 のARスペクトルを次式より求める。

$$
\widetilde{\mathrm{S}}\left(\eta_{\mathrm{p}}\right)=\Delta \tau \sigma_{\mathrm{e}}^{2}\left|\frac{1}{\mathrm{~A}\left(\mathrm{e}^{-\mathrm{j} 2 \times \eta_{\mathrm{p}} \tau \tau}\right)}\right|^{2}
$$

ここに, $\eta_{\mathrm{p}}$ は次式で定義する無次元周波数

$$
\eta_{\mathrm{p}}=\mathrm{n} \cdot{ }^{\mathrm{P}} \mathrm{L}_{\mathrm{q}} / \overline{\mathrm{U}}
$$

で， $\mathrm{n}$ は実周波数。また

$$
\sigma_{\mathrm{e}}^{2}=\sigma_{\mathrm{x}}^{2}\left\{1+\sum_{\mathrm{i}=1}^{\mathrm{m}} \mathrm{a}_{\mathrm{i}}(\mathrm{m}) \rho_{\mathrm{i}}\right\}
$$

$A\left(e^{-j 2 \pi \eta_{p} \Delta \tau}\right)$

$$
=1+\sum_{i=1}^{m} a_{i}(m) e^{-j 2 \pi \eta_{p i} \Delta \tau}
$$

で， ${ }^{2}$ は時系列波形の分散である。

4. AR次数 $\mathrm{m}$ を変えて上記 $1 \sim 3$ を繰り返し, 対応するARスペクトルを目標パワースペクトルと 比較検討する。Fig. 2に上記手順を示す。

\section{3. 乱流モデルに対するARモデルの特性}

今回検討したのはDryden型とKármán型の乱流モ デルについてそれぞれの u成分およびv成分であ る。ここで本コーナーの主旨に甘え紙面節約のた め各乱流モデルの数式表現の揭載を文献6)の参照 に替えることをお許し願いたい。ただ，以下で用 いている無次元パワースペクトルと無次元周波数 は実周波数 $\mathrm{n}$ のパワースペクトルS (n)に対して以 下のように定義している。 


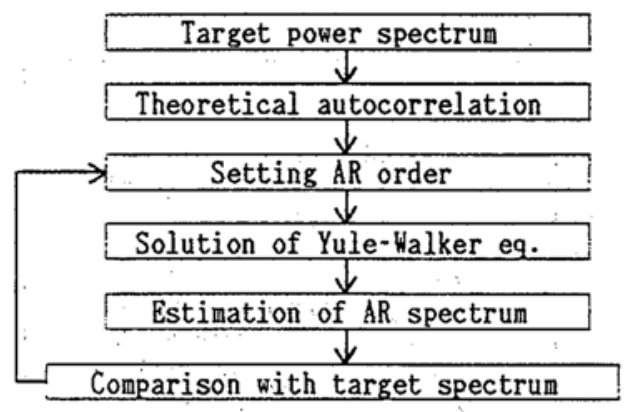

Fig. 2 Estimation Procedure of AR method

u成分の無次元パワースペクトル：

$$
\widetilde{S u}\left(\eta_{u}\right)=\frac{\bar{U} \cdot S_{u}(n)}{\overline{u^{2}} \cdot{ }^{n} L_{x}}
$$

$\mathrm{u}$ 成分の無次元周波数 :

$$
\eta_{\mathrm{u}}=\mathrm{n} \cdot{ }^{\mathrm{u}} \mathrm{L}_{\mathrm{x}} / \overline{\mathrm{U}}
$$

$\mathrm{v}$ 成分のパワースペクトル：

$$
\widetilde{S}_{v}\left(\eta_{v}\right)=\frac{\bar{U} \cdot S_{v}(n)}{\overline{v^{2} \cdot v} L_{y}}
$$

$\mathrm{v}$ 成分の無次元周波数：

$$
\eta_{\mathrm{v}}=\mathrm{n} \cdot{ }^{v} \mathrm{~L}_{\mathrm{y}} / \overline{\mathrm{U}}
$$

指数関数で表されるDryden型自己相関関数はホ ワイトノイズ $\mathrm{e}(\mathrm{t})$ を入力とする次式の 1 階常微分 方程式

$$
\dot{x}(t)+x(t)=e^{\prime}(t)
$$

で表わされる連続確率過程 $\mathrm{x} .(\mathrm{t})$ の自己相関係数で あり, Dryden型自己相関係数の離散化モデルは 1 次のARモデルであることが理論的に示される7)。 すなわちDryden型自己相関係数は 1 次のARモデル で正確に表現できるのである。

Fig. 3の最上部は無次元時間間隔 $\Delta \tau$ を0.1で読 み取ったDryden型自己相関係数の理論式を用いて 求めた1次のARモデルの自己相関係数である。予 測どうりこの曲線は理論式に一致している。こ の結果は 2 次以上のARモデルを設定して算定して も同じであった。さらに, m次のARモデルでのAR
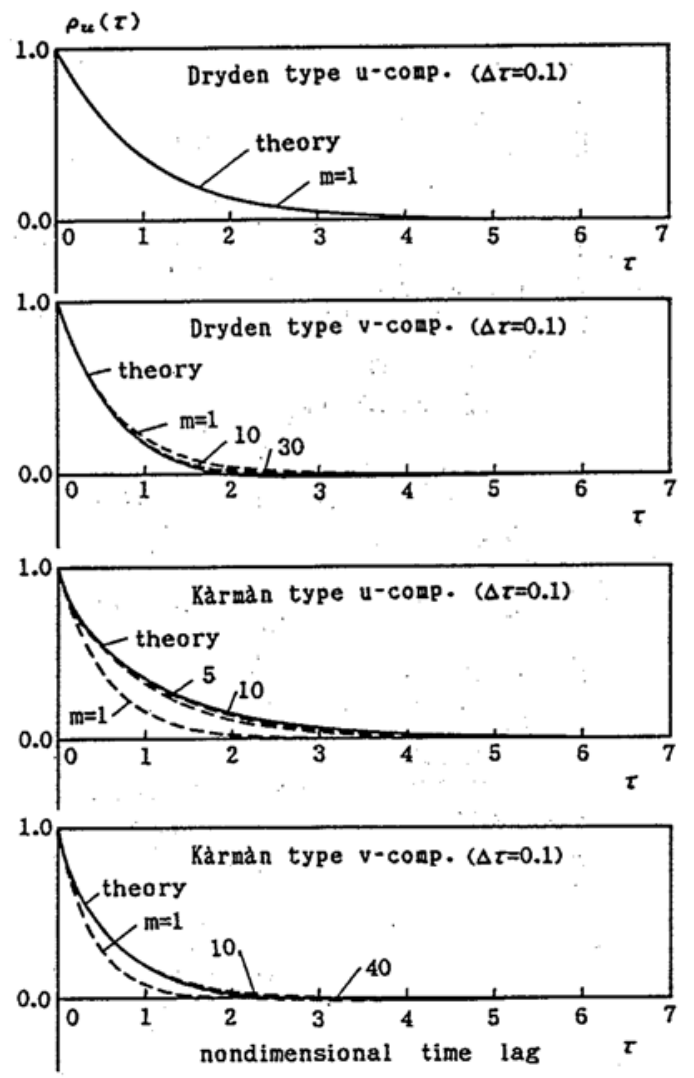

Fig. 3 Autocorrelation coefficients of theoretical and AR model

係数 $\mathrm{a}_{\mathrm{i}}(\mathrm{m}), \mathrm{i}=1,2, \ldots, \mathrm{m}$ の偏相関係数 $\mathrm{a}_{\mathrm{m}}(\mathrm{m})$ が有 する次式の性質

$$
a_{p}(p)=0 \quad(p \geqq m+1)
$$

を調べると $\mathrm{m}=1$ となり, Dryden型自己相関係数 が 1 次のARモデルであることの必要十分条件を満 たしていることも確認できた。

Fig. 3の最上部に示す 1 次のAR係数から計算さ れたARスペクトルとDryden型 u成分のパワースペ クトルをFig. 4の最上部に示す。当然のことでは あるが, 理論スペクトルに良く一致している。た だ無次元周波数 》。が大きくなるに連れて両者の 差が見られるが，これは離散時間間隔 $\Delta \tau$ を大き くすると顕著になり, 逆に小さくすることで改善 できた。

この傾向は他の乱流モデルでも同じであった。 


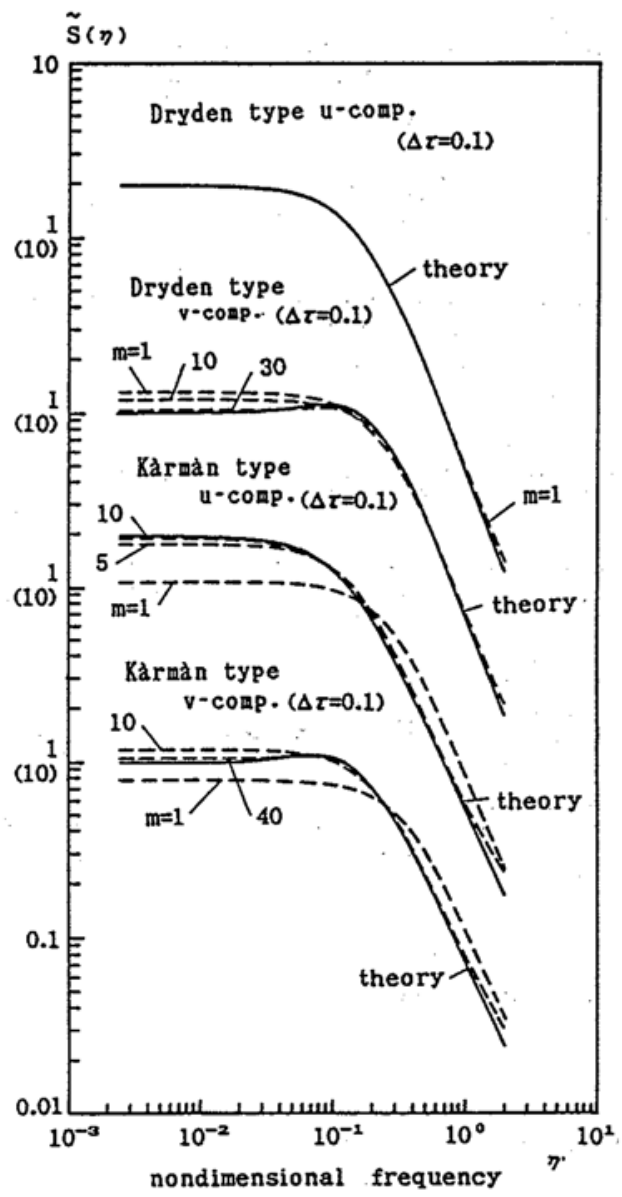

Fig. 4 Power spectrum of theoretical and AR model in standard form

Fig. 5の最上部は無次元離散時間間隔を $\Delta \tau=$ 0.05 とした場合のDryden型 u 成分の対数パワース ペクトルである。スペクトルピークはもちろん高 周波数域まで非常に良く一致している。

以下同様に, $\Delta \tau=0.1 て ゙$ 読み取ったDryden型 $\mathrm{v}$ 成分, Kármán型の u成分および $\mathrm{v}$ 成分の自己相 関係数の理論式をそれぞれ用いて計算したARモデ ルの自己相関係数とARスペクトルを示したのがFig. 3,4および5である。ただし図の縦軸の（）内の值 はそれぞれ対応する乱流モデルの座標値の始まり を示すものある。

Kármán型の u 成分の自己相関係数は図上では

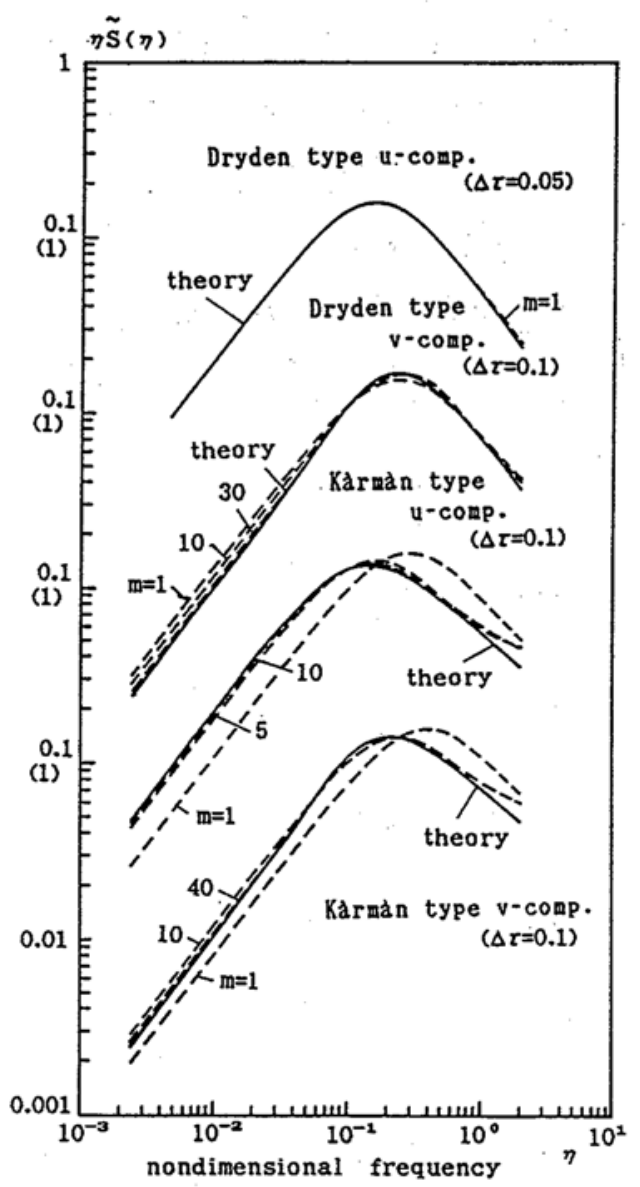

Fig. 5 Power spectrum of theoretical and AR model in logarithmic form

Dryden型のそれに非常に良く似ているが，ARモデ ルへの同定には大きな違いが表れている。

Dryden型 v成分, Kármán型の u成分および $\mathrm{v}$ 成 分の自己相関係数の理論式に対しては, ARモデル の偏相関係数の性質.(13)式を用いた明確な次数決 定はできなかった。しかしながら，各理論式を用 いて計算したARモデルの自己相関係数と理論式を 比較したFig. 3に示すように, AR次数が大きくな るに従い理論式に近づく。 $\mathrm{v}$ 成分の自己相関係数 は負の相関值を示す範囲を持つのが特徴であるが, ARモデルの自己相関係数が負の領域を表現できる のはDryden型ではAR次数が11次以上, Kármán型で 
は16次以上必要であった。このときどちらもAR次 数の使用範囲は理論相関係数の負の領域までには 達していない。パワースペクトルではFig. 4と5に 示すように，視察で良く一致すると言えるのは Dryden型 $\mathrm{v}$ 成分で30次以上, Kármán型 $\mathrm{u}$ 成分で10 次以上, Kármán型 $\mathrm{v}$ 成分では40 50次以上であっ た。しかしながら，各乱流モデルのパワースペク トルの高周波数域の特徵である-2乗則や- $5 / 3$ 乗則 は低いAR次数のときでも良く対応している。離散 時間間隔を小さく採れば，一致する高周波数域を さらに延ばすことができるのはDryden型 u成分の ときと同じである。ただしこの場合はAR次数を大 きくしなければならなかった。

これらの結果をまとめると, Kármán型 $\mathrm{v}$ 成分は 他のモデルに比べて理論值への収束が緩やかでよ ク大きなAR次数を必要とすると言える。

\section{4. 乱れのスケールの算定誤差と偏相関係数の変} 化

前節では, 自己相関係数とパワースペクトルを 図上での視察により比較検討したが, 定量的な判 断規準として, 乱れの積分スケールの算定精度を 検討してみた。Table 1 は各乱流モデルでの縦方 向の乱れの積分スケール値を誤差5\%あるいは $3 \%$ で推定できた最小のAR次数である。ただし，いず れも無次元時間間隔を $\Delta \tau=0.1$ とした場合であ り, 離散間隔を小さくすれば同じ精度を有する最 小次数は大きくなる。

一方, Fig. 6は各乱流モデルに対する偏相関係 数の値を示すもので横軸はAR次数である。この図 とTable 1 とを比べると大体 $10^{-3} \sim 10^{-4}$ 程度にな る偏相関係数を探すことがAR次数決定の判断規準 の一つになりそうである。ただし，Kármán型v成 分ば $\mathrm{m}=8$ で偏相関係数が $10^{-4}$ のオーダーになる 極小値を持つが, このとき乱れのスケールで誤差 20\%を示し，充分な精度に達していなかった。
Table 1 AR order for esitimation error of turbulent scale $(\Delta \tau=0.1)$

\begin{tabular}{|c|c|c|}
\hline turbulent model & error 5\% & error 3\% \\
\hline Dryden u comp. & 1 & 1 \\
\hline Dryden v comp. & 33 & 42 \\
\hline Kà raàn u comp. & 8 & 11 \\
\hline Kà raàn v comp. & 43 & 57 \\
\hline
\end{tabular}

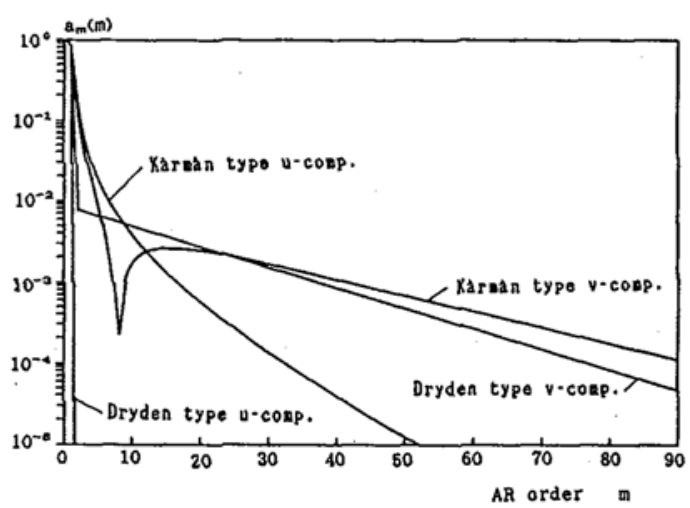

Fig. 6 Partial correlation coefficients of AR model $(\Delta \tau=0.1)$

\section{5. 結び}

Dryden型とKármán型乱流モデルでは, Dryden型 u成分以外は理論的には無限次のARモデルが必要 である。AR次数を大きく設定すれば，精度をより 上げることができるが, 例えば, 乱れの積分スケ ールをある範囲の誤差に収めるには有限次のARモ デルを用いることができる。ここでは無次元時間 間隔 $\Delta \tau=0.1$ に対するこのような有効次数を示 した。無次元時間や偏相関係数の使用あるいは乱 れのスケールの算定精度を基準にした精度検定は, ARモデルの同定精度を保証するものであり, 例え ば, 構造物の逐次風応答計算の外力風速に用いる 実風速シミュレーションなどに利用できると考え られる。

しかしながら, 風速時系列デー夕の自己相関関 数の算定を経たARモデルの同定に上述の次数を直 接適用することはできない。なぜなら上述の論理 
展開では理論相関関数を用いており, 時系列から の自己相関係数の算定誤差がARモデルの同定に及 ほす影響を全く考虑していないからである。

AR次数に時系列デー夕数の平方根を設定した $\mathrm{AR}$ スペクトルを見かけることがあるが，筆者はこの ような次数決定には賛成できない。このようにし て回帰次数を上げることによって，本コーナー前 半で述べた自己相関関数の推定精度の悪い領域を 使用する可能性があるからである。AR次数に大き な影響を与える離散時間間隔の大きさやデー夕長 など, ディジタル解析上のいくつかのパラメータ を総合的に考慮してAR次数を決定する方が良い結 果につながるのではないだろうか。このような観 点からも, 安定性など問題点がないわけではない が，ARモデルを用いる限りにおいては筆者は赤池 のFPE基準を用いた次数決定を使用している。た だし, 出来る限りデー夕長を長くして自己相関係 数の推定精度を上げることが必要である。ある程 度までの無次元周波数域を解析範囲とし, なお且 つ自己相関関数の推定精度を上げようとすれば必 然的にデー夕個数は增大するが, これはAR法を変 動風速の解析に用いる場合には避けられないこと である。

耐風工学を勉強する者にとってはスペクトル解 析法は一つのツールである。筆者はそのツールの
ーユーザーとして筆を執らせて頂いたが，本稿に 対する皆様のご批判を承りたい。

今回は触れる余裕がなかったクロススペクトル などの 2 次元問題やARモデル以外のパラメトリッ クモデルについても機会があれば, 併せてご報告 申し上げたい。

\section{参考文献}

1）岩谷；MEMによるスペクトル解析について, 日本風工学誌, Vol. 35, 1988, pp45-47.

2）前田, 牧野; 変動風速のスペクトル計算法に ついて, 日本建築学会論文報告集, 第300号, 1981, pp19-29.

3）星谷; 確率論手法による振動解析, 鹿島出版会, 1974, 3 章.

4）赤池, 中川 ; ダイナミックシステムの統計的 解析と制御, サイエンス社, 1972, 3 章.

5）前田, 牧野; 大気乱流の平均流方向成分の統 計的性質に関する研究, 日本建築学会論文報 告集, 第287号, 1980,pp77-86.

6) ESDU 74031; Characteristics of atmospheric turbulence near the ground, 1974, pp4-5.

7) Jenkins \& Watts; Spectral Analysis and its applications, Holden-Day, 1968, chap. 5. 